\title{
La diversidad tipológica de los hornos tradicionales de calcinación de yeso en España
}

\section{The typological diversity of traditional gypsum calcination kilns in Spain}

\author{
V. La Spina ${ }^{(*)}$, C.J. Grau Giménez ${ }^{(* *)}$
}

\section{RESUMEN}

El objetivo del artículo es dar a conocer una primera clasificación tipológica de la gran variedad de hornos tradicionales de yeso que aún se conservan en España y que han sido empleados históricamente para la producción de yeso en polvo. Tras la realización del "Estudio del yeso tradicional en España" para Instituto del Patrimonio Cultural de España y de investigaciones posteriores, ha sido posible localizar, visitar y dimensionar un número destacado de hornos de yeso, hoy en día en desuso salvo casos puntuales. En todos ellos, el proceso de calcinación se ha fundamentado en el mismo principio, la deshidratación de la piedra de yeso, pero en conjunto presentan diferencias constructivas, morfológicas y funcionales que se han analizado en detalle. Además, los resultados obtenidos evidencian la existencia de variaciones tipológicas a nivel geográfico así como diferencias en la carga de los hornos y la producción obtenida.

Palabras clave: Horno, yeso, tipos, construcción, materiales, forma, dimensiones, España.

\section{ABSTRACT}

The aim of this article is to present a first typological classification of the great variety of traditional gypsum kilns that are still conserved in Spain and that have been used for the production of powdered gypsum historically. Following the "Study of traditional gypsum in Spain" for the Spanish Cultural Heritage Institute and subsequent research, it has been possible to locate, visit and mesure an outstanding number of gypsum kilns, which are currently in disuse except for specific cases. In all of them, the calcination process has been based on the same principle, the dehydration of gypsum stone, but they present constructive, morphological and functional differences as a whole that have been analyzed in detail. In addition, the achieved results show the existence of typological variations at a geographical level as well as differences in the kilns' load and the production output.

Keywords: Kiln, gypsum, types, construction, materials, shape, dimensions, Spain.

(*) Doctor Arquitecto. Profesor Contratado Doctor. Universidad Politécnica de Cartagena, Cartagena (España).

(**) Arquitecto. Valencia (España)

Persona de contacto/Corresponding author: vinlaspi@hotmail.com (V. La Spina)

ORCID: https://orcid.org/oooo-0oo1-8917-2156 (V. La Spina); https://orcid.org/oooo-0oo1-5147-8811

(C.J. Grau Giménez)

Cómo citar este artículo/Citation: La Spina, V.; Grau Giménez, C.J. (2020). La diversidad tipológica de los hornos tradicionales de calcinación de yeso en España. Informes de la Construcción, 72(557): e334. https://doi.org/10.3989/ic.71670

Copyright: (c) 2020 CSIC. Este es un artículo de acceso abierto distribuido bajo los términos de la licencia de uso y distribución Creative Commons Reconocimiento 4.o Internacional (CC BY 4.0). 


\section{INTRODUCCIÓN}

En la tradición constructiva española, el yeso, en todas sus variantes $(1,2)$, ha sido un material ampliamente utilizado en todo tipo de edificios para realizar desde simples blanqueos hasta elementos estructurales y sobre todo si el recurso mineral abundaba en el entorno próximo. Específicamente, en toda la parte oriental del territorio español donde hay afloramientos yesíferos, como pone de manifiesto la cartografía geológica (3, 4, 5). Así pues, en el pasado, ha sido un recurso largamente explotado para su uso como material de construcción, debido también a su fácil extracción, transformación y puesta en obra.

El yeso en polvo se obtiene tras someter la piedra extraída a un proceso de transformación que consiste básicamente en su deshidratación parcial en un horno, su molienda y su posterior cribado. Según Villanueva (6), en el caso específico de una producción artesanal de yeso, ello supone que dicha deshidratación se produzca mediante la calcinación del aljez en hornos tradicionales discontinuos. Es decir, en hornos en los que la piedra de yeso extraída de la cantera y con diferentes tamaños se dispone en su interior creando uno o varios hogares para introducir el combustible necesario durante todo el proceso.

En la bibliografía especializada e incluso en los textos históricos como por ejemplo en la tratadística española $(1,7,8)$, los hornos tradicionales de yeso se describen simplemente bien como similares a los empleados para la producción de la cal, es decir como hornos tipo cuba de planta circular, pero de menores dimensiones; o bien como construcciones, cubiertas o no, de planta cuadrangular (9). Sin embargo, tal y como puntualiza en su tratado Pereir y Gallego (10) los hornos en los que se calcina el yeso se hacen de distintas figuras según la costumbre del país porque no en todos los sitios se hace igual aun cuando en la esencia sea lo mismo. Esta afirmación se ha podido corroborar gracias al "Estudio del yeso tradicional en España. Yacimientos, canteras, hornos y la arquitectura tradicional, su estado de conservación y propuestas de itinerarios visitables para su revalorización y difusión" (1) y a investigaciones complementarias posteriores $(11,12)$, que han permitido localizar, visitar y dimensionar hornos tradicionales de yeso en 31 provincias españolas y en consecuencia tener una visión general a nivel nacional de los diferentes tipos de hornos de yeso empleados históricamente para la producción de yeso en polvo. Algunos de ellos incluso, en funcionamiento hasta casi los años 80 del siglo XX en determinadas zonas rurales de España (11), existiendo por tanto una convivencia prolongada durante años de los dos tipos de yesos, tanto del artesanal como industrial, según la diferenciación de Villanueva (6).

Así pues, el principal objetivo del presente artículo es dar a conocer la gran diversidad tipológica de hornos tradicionales de yeso que aún se conservan en el territorio nacional, ya que han jugado un papel protagonista en la producción de yeso en polvo empleado en las construcciones históricas y tradicionales. Para ello, se ha realizado una exhaustiva búsqueda y un análisis pormenorizado de sus principales características desde una perspectiva constructiva, morfológica y funcional, que ha permitido además evidenciar rasgos distintivos a nivel geográfico.

\section{1. Área del estudio: la España yesífera}

El área en la que se ha desarrollado el estudio corresponde con el territorio de la península ibérica que se caracteriza por presentar afloramientos de yeso, y donde además han sido ex- plotados históricamente para la producción de yeso en polvo. En concreto, coincide con la vertiente oriental de la península, en la cual además el aljez es el que más aflora en la superficie, según los diferentes mapas geológicos elaborados por el Instituto Geológico y Minero de España (IGME) y la cartografía confeccionada por Riba y Macau (3). En los primeros, básicamente se indican las unidades litológicas con posible presencia de yeso y que además presentan cierta potencia, es decir, profundidad del depósito, así como otras sustancias minerales como calizas, margas, arcilla, dolomías, etc. En cambio, en el mapa de Riba y Macau (3) que ha sido revisado por Sanz (4) se indica la localización y la extensión de los afloramientos de yeso en España y se establece también que $35.487 \mathrm{~km} 2$, el $7,2 \%$ de la superficie española, está ocupada por yeso o materiales con un contenido significativo de éste. Por lo tanto, el estudio define esta área como "España yesífera", ya que representa el 58,5\% de la superficie y comprende la mitad oriental de la península, además de Asturias, Valladolid, Palencia, Cádiz, Málaga, Sevilla así como Córdoba (4). La zona descrita, a su vez, coincide en gran medida con las áreas de la península en las que crece la vegetación gipsícola, que además ha sido empleada con frecuencia como combustible en los hornos de yeso, y que se caracteriza no solo por la presencia de afloramientos de yeso, sino también por tener unas condiciones climáticas áridas o semiáridas (13).

La cartografía descrita ha sido de gran ayuda para definir el área del estudio y en especial modo localizar los yacimientos de yeso y sobre todo aquellos explotados en el pasado para producir yeso en polvo (Figura 1). No obstante, cabe matizar que la simple existencia de un afloramiento de yeso no implica su necesaria explotación, ni tampoco la ausencia de una zona o población en la cartografía descrita supone que no haya depósitos de yeso ya que puede deberse a la escala representada o a la escasa potencia de los mismos. Por ello, igualmente puede haberse extraído y producido yeso de forma artesanal en áreas no evidenciadas en los mapas, pero de manera puntual para consumo propio, una práctica, que por otra parte, ha sido muy frecuente en numerosas zonas rurales de España.

\subsection{Breve apunte sobre el proceso artesanal y tradicional de calcinación del yeso}

El yeso en polvo empleado como material de construcción se obtiene deshidratando parcialmente el aljez en un horno de

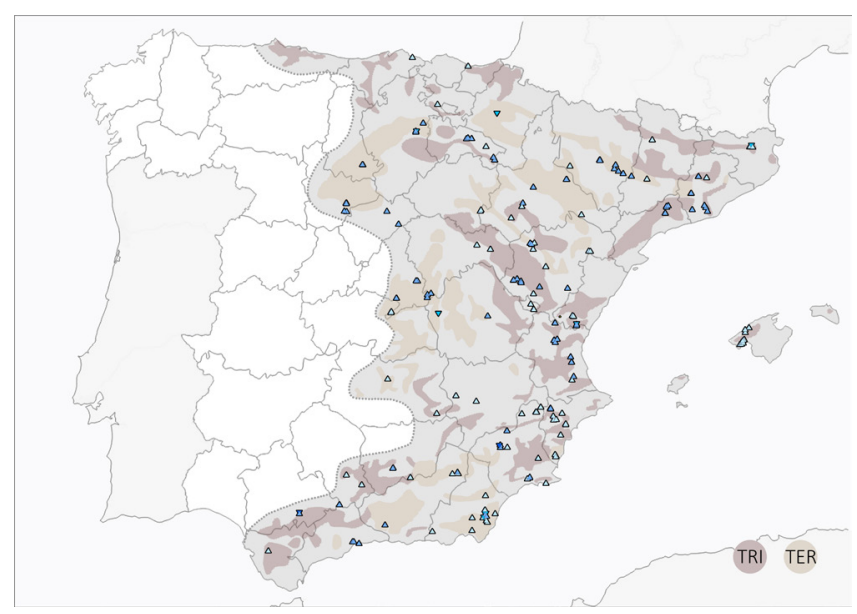

Figura 1. Mapa de la "España yesífera” mostrando el área de estudio, las edades geológicas del yeso y los centros de trasformación inventariados (Mapa: Autor 2, 2018). 
calcinación. Por una parte, desde una perspectiva científica, la piedra se somete a temperaturas que pueden oscilar en un horno tradicional aproximadamente, de entre $120^{\circ} \mathrm{C}$ hasta los $900^{\circ} \mathrm{C}(4,14)$, dependiendo del tipo de combustible empleado y de la zona específica del horno. El objetivo es que el yeso, es decir, el sulfato cálcico dihidrato ( $\mathrm{CaSO}_{4}$ 2H2O), pierda parte del agua que contiene, tanto la de cantera como la de cristalización. Además, dependiendo de la temperatura y la presión alcanzadas, así como de la zona concreta del horno o el tamaño de la piedra, esta pérdida puede ser parcial o total pudiéndose obtener diferentes fases de la deshidratación (Tabla 1), y por lo tanto yesos multifásicos con prestaciones y cualidades únicas, muy diferentes a las de los yesos industriales que se comercializan en la actualidad, ya que son yesos monofásicos o bifase $(4,6)$.

Tabla 1. Temperaturas de calcinación y fases del yeso obtenidas en un horno tradicional de yeso $(4,14,15)$.

\begin{tabular}{|l|l|l|}
\hline $\begin{array}{c}\text { Temperatura } \\
\text { de Calcinación }\end{array}$ & \multicolumn{1}{|c|}{$\begin{array}{c}\text { Fase } \\
\text { mineral }\end{array}$} & \multicolumn{1}{c|}{ Nombre } \\
\hline Estado natural & $\mathrm{CaSO} 42 \mathrm{H} 2 \mathrm{O}$ & Dihidrato - Yeso o aljez \\
\hline $120-180^{\circ} \mathrm{C}$ & $\mathrm{CaSO} 41 / 2 \mathrm{H} 2 \mathrm{O}$ & Hemihidrato $(\beta)$ \\
\hline $180-300^{\circ} \mathrm{C}$ & $\mathrm{CaSO} 4$ & Anhidrita III (soluble) \\
\hline $\begin{array}{l}300-700^{\circ} \mathrm{C} \\
\left(300-500^{\circ} \mathrm{C}\right) \\
\left(500-700^{\circ} \mathrm{C}\right)\end{array}$ & $\mathrm{CaSO} 4$ & $\begin{array}{l}\text { Anhidrita II } \\
\text { (ligeramente soluble) } \\
\text { (insoluble) }\end{array}$ \\
\hline$+1200^{\circ} \mathrm{C}$ & $\mathrm{CaSO} 4$ & Anhidrita I (inestable) \\
\hline $\begin{array}{l}+1350^{\circ} \mathrm{C} \\
\left(900^{\circ} \mathrm{C}\right)\end{array}$ & $\mathrm{CaO}+\mathrm{SO}_{3}$ & $\begin{array}{l}\text { Yeso hidráulico } \\
\text { (en presencia de arcillas) }\end{array}$ \\
\hline
\end{tabular}

Por otra parte, técnicamente, el proceso de calcinación consiste, en primer lugar, en calentar moderadamente la piedra de yeso para desecarla y eliminar la humedad de cantera y toda el agua que no se halla en estado de combinación, para a continuación aumentar la temperatura y así poder completar la deshidratación. Este proceso normalmente se ha realizado en condiciones climáticas favorables, y su duración puede variar considerablemente de 12 a 36 horas dependiendo de muy diversos factores: la calidad de la piedra, el tipo de combustible (leña, monte bajo, cascarilla, etc.), el estado atmosférico o la forma del horno. Por ello, en el pasado la experiencia del yesero ha sido determinante para establecer en cada caso particular cuando la calcinación había concluido y se ha basado en diferentes criterios relacionados con el color de la piedra situada en la zona superior del horno o en el interior de la bóveda, e incluso con el color del humo o su olor (1).

\section{METODOLOGÍA Y FASES DEL ESTUDIO}

La investigación llevada a cabo se ha fundamentado tanto en fuentes primarias como en fuentes secundarias y ha supuesto una revisión bibliográfica, pero sobre todo una búsqueda in situ mediante un exhaustivo trabajo de campo para localizar los hornos de yeso que aún se conservan en buen estado o que pueden ser visitados a nivel nacional en el área descrita para el desarrollo del estudio. Así pues, la metodología aplicada se ha caracterizado por tener una doble vertiente tanto teórica como práctica y por desarrollarse siguiendo diferentes fases de investigación.

En primer lugar, para conocer cómo eran los hornos de yeso empleados en el pasado se ha consultado bibliografía espe- cífica, es decir, todo tipo de publicaciones, libros, revistas, artículos, etc. además de fuentes oficiales de la administración en todas sus instancias (Comunidades Autónomas, Diputaciones Provinciales, Mancomunidades, Ayuntamientos, etc.); asociaciones profesionales; museos etnográficos; investigadores; asociaciones de personas interesadas en ellos; así como páginas web y recursos de internet de todo tipo (foros, blogs, páginas comerciales, etc.). Ello ha permitido empezar a elaborar un primer inventario de los hornos tradicionales de yeso existentes y además llevar a cabo una primera localización de los mismos.

En segundo lugar, teniendo en cuenta que con frecuencia los centros de transformación y producción del yeso en polvo se sitúan en las proximidades de los puntos de extracción, a través de la identificación de canteras y minas de yeso se ha intensificado su búsqueda y localización. En este sentido, sobre todo se han consultado las bases de datos del Instituto Geológico y Minero de España (IGME), de especial modo las memorias de los mapas de rocas industriales del IGME redactadas en los años 70 del siglo XX, además de los mapas geológicos ya citados en los que se indican las áreas con recursos yesíferos. Así como, la información recogida en el catastro minero sobre el derecho minero de las canteras de yeso, y aquella existente en las diversas secciones específicas sobre minería en las consejerías de las diferentes Comunidades Autónomas en relación con las canteras en explotación y las registradas en el pasado.

En tercer lugar, tras la localización de un número considerable de hornos se ha procedido a su visita para la toma de datos in situ, realizando un trabajo de campo por las principales zonas yesíferas de España. Además, durante las visitas se han contactado personalmente artesanos, albañiles y profesionales o se han entrevistado vecinos para conocer de primera mano su localización y funcionamiento e incluso se ha presenciado la calcinación de un horno tradicional en el marco de unas jornadas de investigación (16). Específicamente, ha sido posible identificar más de 200 centros de transformación, algunos compuestos solamente por un único horno mientras que otros por conjuntos de ellos, obteniendo así datos generales de un total de 365 hornos diferentes y datos específicos de 172 al haberse podido dimensionar y levantar gráficamente.

Por último, con toda la información recopilada se ha procedido a su sistematización en tablas, gráficas y mapas geográficos para facilitar su análisis desde varios puntos de vista, haciendo especial hincapié sobre todo en cuestiones constructivas, morfológicas y funcionales que han permitido establecer semejanzas y diferencia entre los diferentes casos inventariados, visitados o dimensionados durante el estudio. Y en definitiva, poder elaborar una primera clasificación tipológica que contemple la gran variedad de hornos utilizados históricamente para la producción del yeso en polvo en España.

\section{RESULTADOS DEL ESTUDIO: TIPOS DE HORNOS TRADICIONALES DE YESO EN ESPAÑA}

En general, los hornos tradicionales de yeso inventariados son construcciones muy sencillas y en ocasiones rudimentarias, semienterradas en desniveles del terreno, aunque no siempre es así, que se localizan principalmente cerca de los 
puntos de extracción de la piedra, es decir, cerca de las canteras o las minas. En caso contrario, se sitúan bien en instalaciones o fábricas situadas cerca de vías de comunicación: caminos, carreteras o vías férreas para facilitar su distribución posterior o bien, en el pasado, junto a las obras donde iba a ser empleado el yeso para controlar mejor su deshidratación. Además, a lo largo de los siglos y en cada zona concreta de la geografía yesífera española el tipo de horno empleado para la producción de yeso en polvo ha variado relativamente poco e incluso en los años 60 del siglo XX se construyeron hornos discontinuos de yeso ex novo como los tradicionales en las localidades de Cehegín (Murcia) y Gestalgar (Valencia) $(1,11)$.

Sin embargo, al analizar con detalle todos los hornos inventariados, visitados o dimensionados, éstos presentan diferencias considerables de tipo constructivo, material, geométrico, dimensional, configurativo, funcional, etc. Por lo tanto, a continuación, de forma sistematizada y ordenada, se intentan abordar los principales criterios de clasificación identificados tras el estudio y análisis realizado.

\subsection{Aspectos constructivos: técnicas y materiales}

La forma más sencilla, rudimentaria e inmediata de calcinar yeso, cuando la cantidad que se deseaba obtener era escasa, ha sido mediante pequeños socavones excavados en la tierra, que muchas veces eran los mismos que resultaban de la extracción de la piedra. En ellos, usando piedras de gran tamaño se formaba un hogar en la parte baja con una abertura para permitir la alimentación del fuego (9). Sin embargo, también existen en España hornos excavados de mayor envergadura situados principalmente en una ladera para aprovechar el desnivel del terreno, y que a diferencia de los simples socavones descritos son de carácter permanente, es decir, se excavaron no para la calcinación puntual de un poco de aljez sino para su uso continuado y en consecuencia también poseen mayores dimensiones. Ejemplos destacados de esta tipología de hornos se han encontrado principalmente en la provincia de Granada, en las localidades de Castillejar y Arenas del Rey (Figura 2A), aunque también en Marchalico Viñicas, Sorbas (Almería), en Peraltilla (Huesca), en Pira (Tarragona) o en Andilla (València).

De igual modo, en ocasiones, los hornos son también construcciones semi-excavadas como en los casos de las poblaciones de Iscar (Valladolid), Fitero (Navarra) o Linares de Mora (Teruel) ya que presentan únicamente un frente de fábrica, mientras que las restantes partes están excavadas en la ladera. No obstante, los hornos más frecuentes y generalizados son los construidos, que también suelen estar situados en una pendiente. En este sentido, la construcción más simple, independientemente del tipo de fábrica, podría definirse de forma general como una sencilla fábrica, cilíndrica o paralelepípeda, con altura variable y una abertura en el frente, bien de toda su altura o bien parcial, para cargar el horno de aljez e introducir el combustible. En consecuencia, desde el punto de vista constructivo en España es posible diferenciar hasta tres tipologías diferentes de hornos de yeso: los excavados (5\%), los semi-excavados (3\%) y los construidos (92\%) con diferentes fábricas y técnicas.

Asimismo, atendiendo a las técnicas constructivas empleadas para la construcción de los hornos de yeso, éstas pueden ser muy variadas desde simples fábricas de piedra en seco, mam- postería, ladrillo o adobe hasta fábricas compuestas o con refuerzos. Según los datos recopilados, la gran mayoría de los hornos inventariados construidos o semi-excavados, concretamente el $82 \%$, son construcciones de una simple hoja de mampostería levantadas con piedra resistente a las altas temperaturas que se alcanzan durante la calcinación. Generalmente, se trata de piedra de tipo caliza, pero con frecuencia ésta es incluso de aljez o una mezcla de ambas tomada con mortero o pasta de yeso. $\mathrm{Y}$ únicamente en algunos escasos casos, tan solo en el $23 \%$, la fábrica de mampostería se haya revestida exteriormente con un mortero de yeso como en los hornos situados en la localidad madrileña de Valverde de Alcalá o en Las Minas, Hellín (Albacete). De igual modo, en ocasiones se combina la mampostería con refuerzos puntuales de fábrica de ladrillo en esquinas, dinteles, hiladas, remates, etc.; y en casos excepcionales con refuerzos metálicos o de hormigón armado (figura $2 \mathrm{C}$ ) tan solo en los dinteles, y sobre todo en hornos que han sufrido reparaciones o intervenciones más recientes. En cambio, los hornos de fábricas de ladrillo, de piedra en seco o de adobe son muy escasos, siendo respectivamente tan solo el $11 \%, 5 \%$, y $2 \%$ del total de hornos inventariados durante el estudio realizado.

Igualmente, cabe destacar que hay casos puntuales de hornos que presentan una diferente tipología de fábrica en el exterior con respecto al interior, al ser construcciones compuestas por 2 hojas, y que representan únicamente el $7 \%$ de los casos analizados. Así pues, hay hornos en los que se combina una fábrica de mampostería exterior con una de ladrillo interior o viceversa (Figura 2D). Además, dependiendo de las dimensiones y la envergadura del horno, éstos pueden tener también refuerzos laterales a modo de contrafuertes, principalmente de mampostería, pero también de ladrillo, para contrarrestar los posibles empujes que la carga de yeso pudiera provocar sobre la pared frontal (Figura $2 \mathrm{C}$ ).

Por último, geográficamente (Figura 3), cabe señalar como los hornos de mampostería se distribuyen de forma homogénea a lo largo de todo el territorio, mientras que el caso particular de aquellos de fábrica de adobe se localizan principalmente en las provincias de Valladolid, Segovia, Huesca y Teruel, con ejemplos destacados en Portillo, Valle del Tabladillo, AzanuyAlins (Figura 2B) y Bañón. Así como, la existencia de provincias en las que los hornos son únicamente de mampostería y otras en las hay que más diversidad de materiales, como en el caso de Teruel.

\subsection{Aspectos morfológicos: configuración de los hornos de yeso}

La vasta variedad morfológica que presentan los hornos de yeso inventariados ha impuesto la necesidad de establecer un segundo nivel de análisis para poder abordar factores más específicos como son su geometría, forma, dimensión, capacidad volumétrica, disposición y número, como se detalla a continuación.

\subsubsection{Geometría y forma de los hornos de yeso}

A grandes rasgos en España existen principalmente dos tipos de hornos de yeso dependiendo de la geometría de su planta, ya que la gran mayoría son de planta circular o con una geometría similar (semicircular, elíptica, oblonga, etc.) siendo el $81 \%$ del total de hornos inventariados frente a tan solo el $15 \%$ de las construcciones con planta cuadrada o rec- 


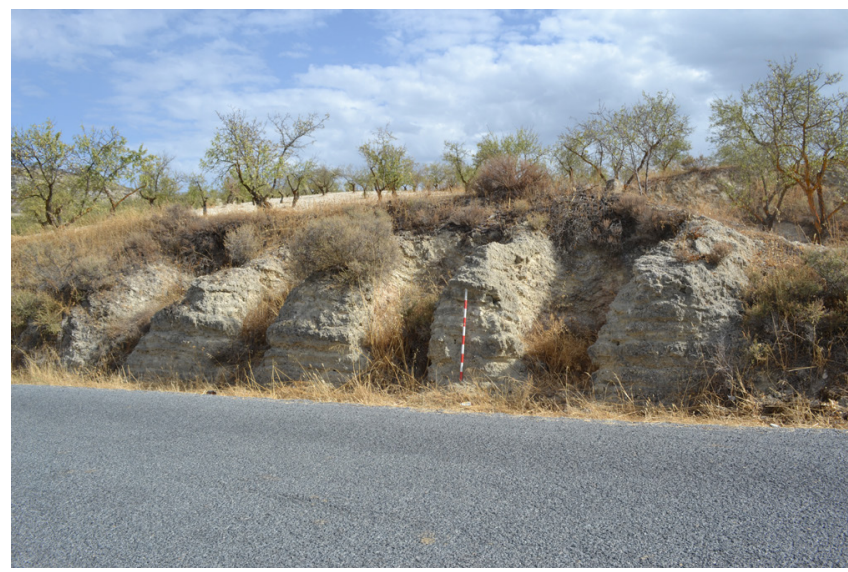

A. Hornos excavados en el Cortijo La Loma, Arenas del Rey, Granada.

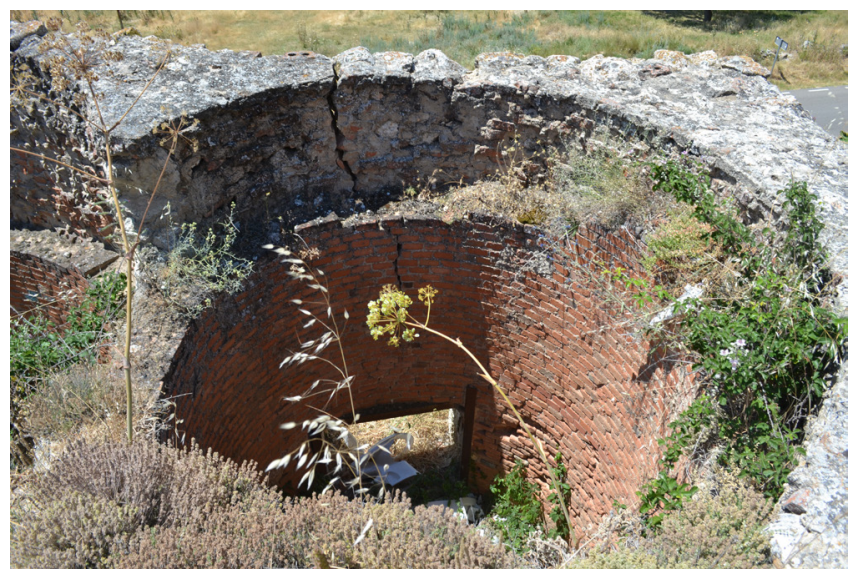

C. Hornos construidos con una hoja exterior de mampostería y una interior de ladrillo en Diebres, Guadalajara.

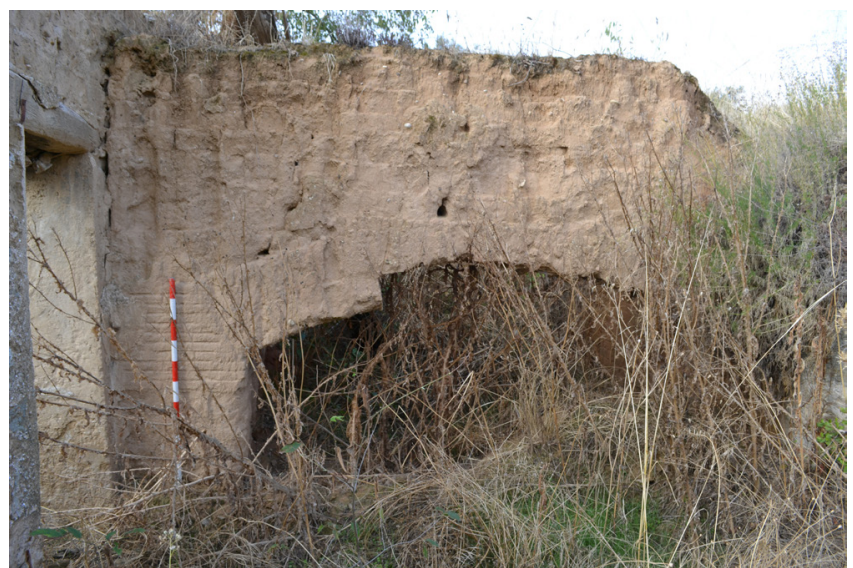

B. Horno semi-excavado de fábrica de adobe en Azanuy-Alins, Huesca.

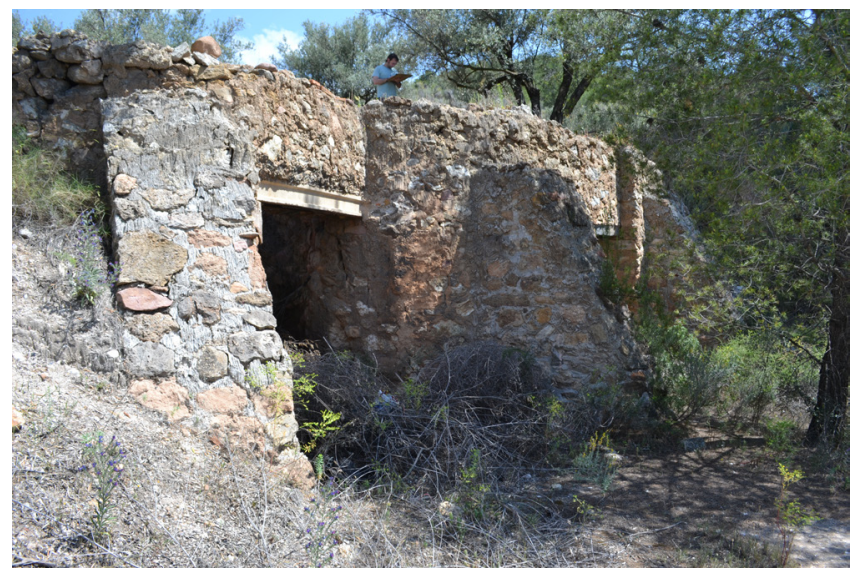

D. Hornos construidos de fábrica de mampostería con contrafuertes en Segorbe, Castellón.

Figura 2. Imágenes de diferentes hornos de yeso según aspectos constructivos (Fotos: Autores, 2016).

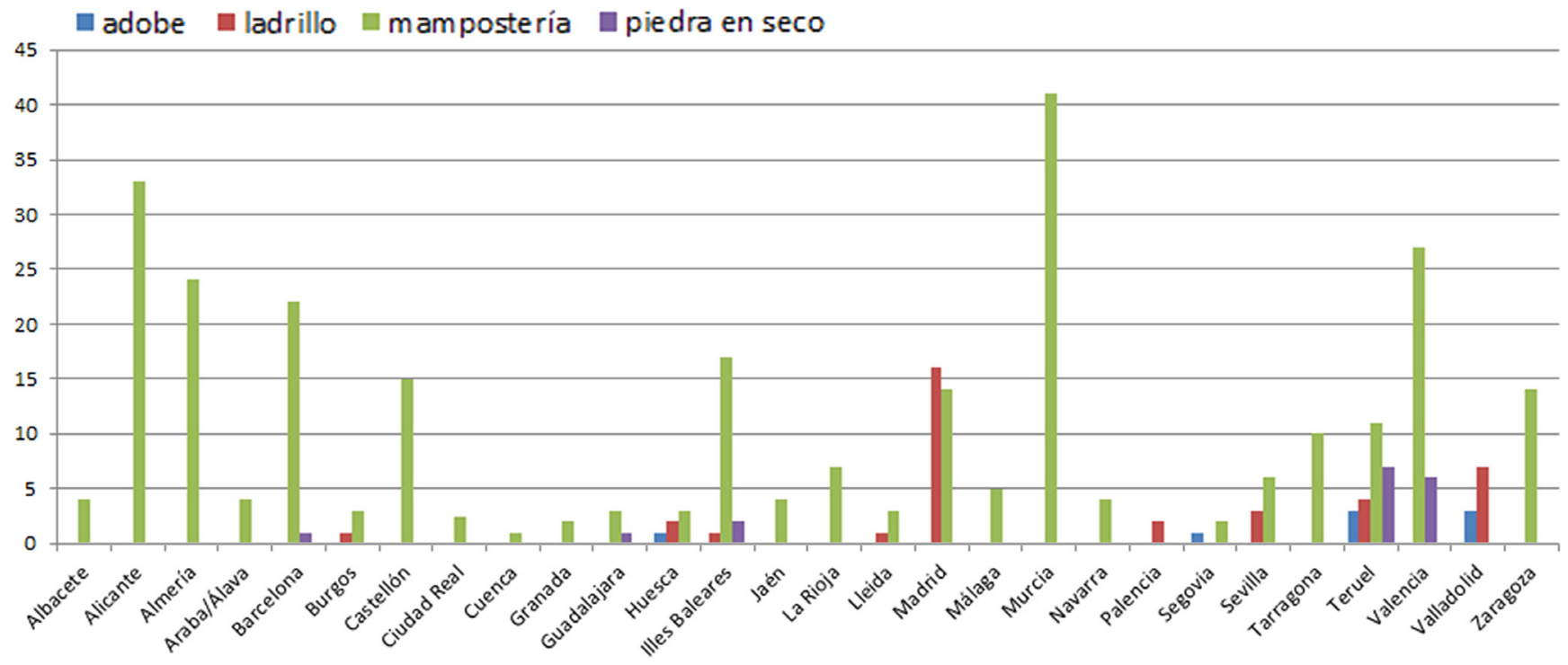

Figura 3. Gráfica de la distribución geográfica de los hornos de yeso inventariados según la materialidad de la fábrica exterior.

tangular. No obstante, también cabe destacar los escasos casos de hornos con una planimetría que combina ambas geometrías, el círculo y el cuadrado, por lo que tienen una planta en forma de herradura y representan al $4 \%$ del total de hornos analizados. Además, por norma general, la sección vertical de los hornos suele ser recta (94\%), aunque en menor medida también hay hornos con una forma troncocónica o troncocónica invertida (6\%), es decir, con dimensiones diferentes en la base y en la coronación, para favorecer el tiro del horno y por consiguiente la calcinación (primer caso) o para facilitar el montaje del hogar y la carga (segundo caso) (Figura 4A). 


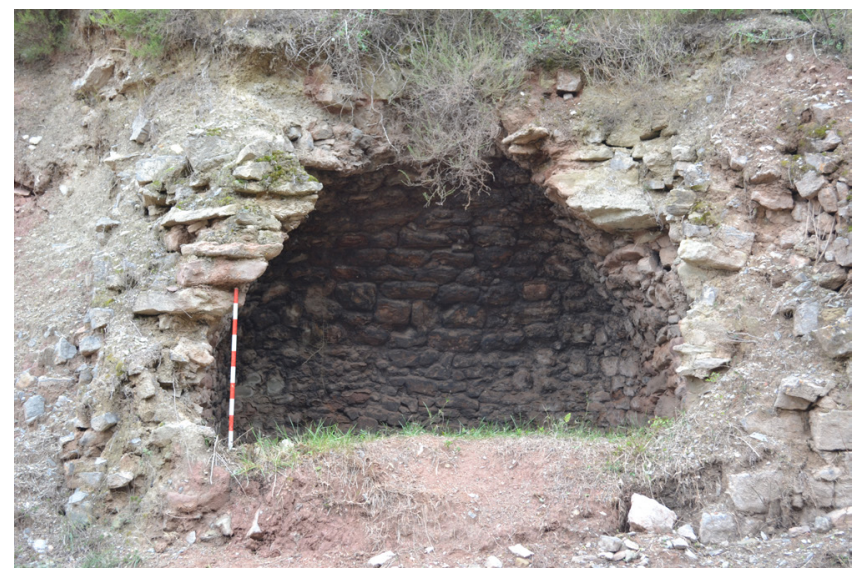

A. Horno de planta elíptica y sección troncocónica en Súria, Barcelona.

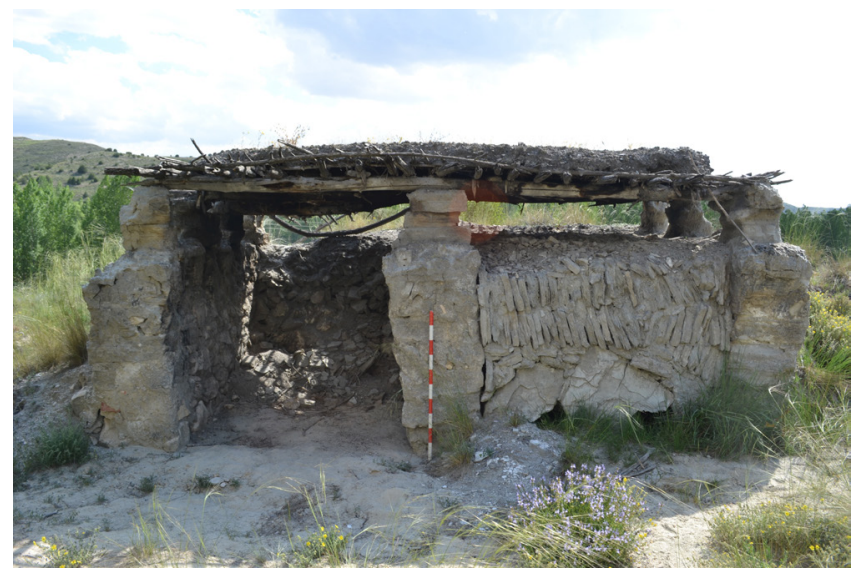

C. Horno de planta rectangular, sección recta y con cubierta en Navarrete del Río, Calamocha, Teruel.

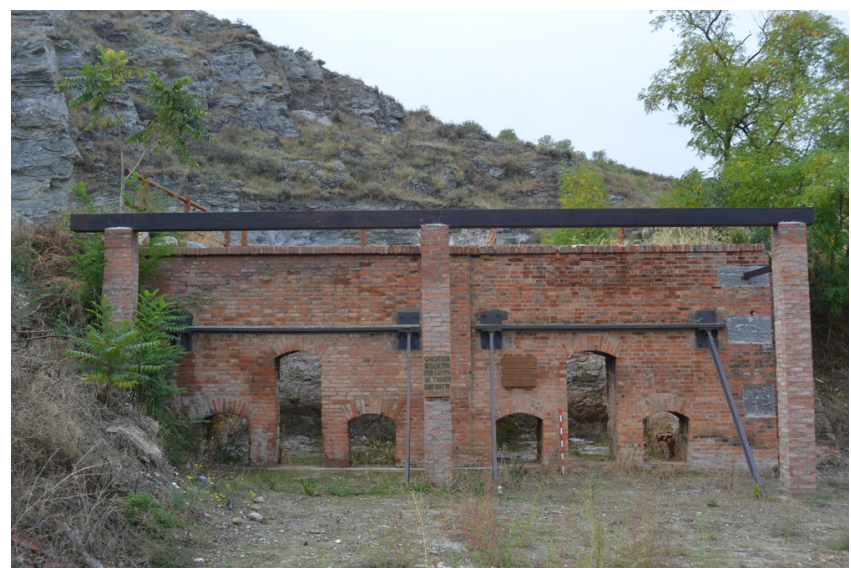

B. Hornos de planta rectangular, sección recta y frente cerrado con 3 aberturas en San Esteban de Litera, Huesca.

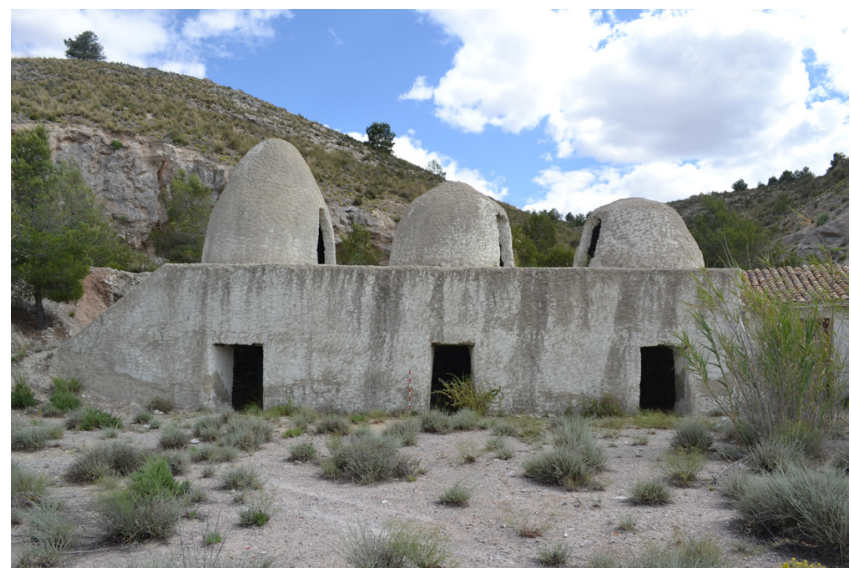

D. Hornos de planta circular, sección recta y cerrados en Villena, Alicante.

Figura 4. Imágenes de diferentes hornos de yeso según aspectos morfológicos: geometría y forma (Fotos: Autores, 2016).

Asimismo, comúnmente por una parte son construcciones cilíndricas con un frente completamente abierto o en su lugar con una pequeña abertura que funciona a modo de puerta, de altura variable, para cargar el horno de aljez y para introducir el combustible. O por otra parte, son estructuras paralelepípedas compuestas únicamente por tres muros cuyo frente se cierra cuando se carga el horno de aljez o íntegramente cerradas, pero con una o varias aberturas frontales. En consecuencia, los tipos de alzados se caracterizan por ser bien completamente abiertos (34\%) o bien cerrados (66\%) con una o más aberturas (Figura 4B), de igual o diferente tamaño, situadas en la misma o distinta cota, siendo lo más frecuente una simple abertura, aunque también se han identificado hornos con múltiples aberturas inferiores laterales, como los casos de Gestalgar (Valencia) o Vallirana (Barcelona) (1).

Además, los hornos pueden estar completamente expuestos a las inclemencias del tiempo, siendo lo más frecuente, es decir, sin ningún elemento que los proteja de la lluvia o el viento. No obstante, en el caso de querer proteger el aljez de la lluvia, los hornos pueden tener una cubierta superior, hecha a partir de una simple estructura de madera, un entramado de cañizo, tierra y ceniza, en los casos más rudimentarios (Figura 4C), o de una estructura de viguetas y bovedillas prefabricadas en los ejemplos remodelados o más recientes. Sin embargo, la tipología más singular de horno de yeso la constituyen los hornos rematados con una forma cónica truncada o "capilla" con una perforación para facilitar el tiro del horno y aberturas en el ni- vel superior para la carga y descarga. Esta variante de horno cerrado es frecuente en la zona de Villena (Figura 4D) (17), Castalla, Petrer, etc. en la provincia de Alicante, pero también en alguna localidad de Zaragoza como La Almunia de Doña Godina o de Almería. Por lo tanto, en función del tipo de cubrición o protección frente a las inclemencias se pueden diferenciar entre hornos descubiertos, cubiertos y cerrados, siendo los primeros el $85 \%$ del total de los hornos inventariados, mientras que los demás el $11 \%$ y el $4 \%$ respectivamente.

Por último, desde un punto de vista geográfico, según el mapa (Figura 5) existe una clara distribución de los hornos de planta circular o similar y de aquellos con planta cuadrangular o de herradura. Además, se aprecia como hay regiones, en las que es posible encontrar más de una tipología e incluso todas como en Illes Balears, Teruel, Valladolid o Zaragoza; así como, la significativa presencia de hornos únicamente de planta circular en las provincias del sur de España y en cambio de planta cuadrangular exclusivamente en la zona del norte de la península.

\subsubsection{Dimensión y capacidad volumétrica de los hornos de yeso}

Igualmente, a lo largo de la "España yesífera", es posible encontrar hornos de muy variadas dimensiones, pudiéndose definir, tras analizar las principales variables dimensionales de un horno: diámetro, anchura, profundidad, altura, volu- 


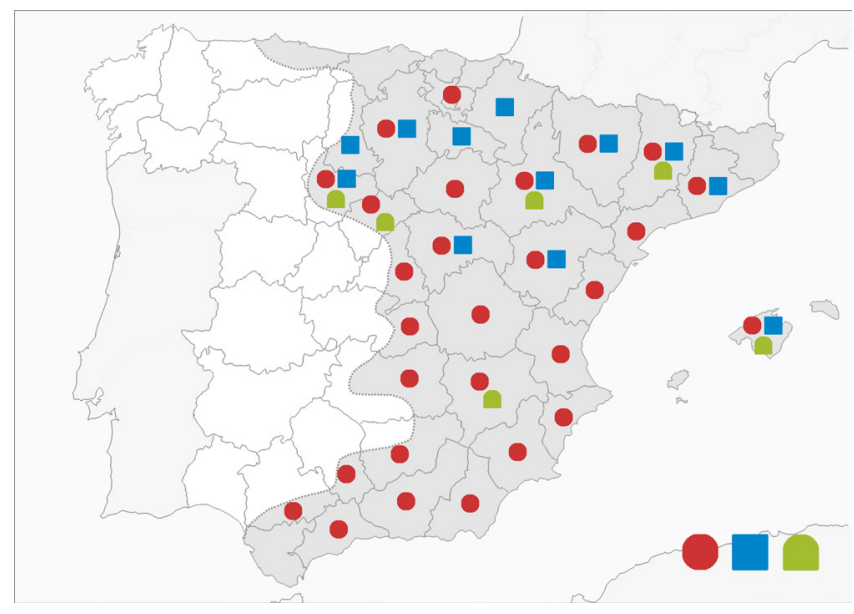

Figura 5. Mapa que muestra la distribución geográfica de los tipos de planta de los hornos de yeso inventariados (Mapa: Autor 2, 2018).

men, etc. tres categorías en función de su tamaño: hornos pequeños, medianos y grandes. En concreto, se han obtenido datos en 167 de los 172 hornos de yeso visitados y dimensionados, al ser imposible en algunos de los casos debido al peligroso estado de conservación y en otros debido a la ubicación de explotaciones apícolas (práctica frecuente). Así pues, teniendo en cuenta la dimensión principal medida en la base del horno, siendo bien el diámetro en hornos circulares, bien el eje mayor en los elípticos o bien el ancho o la profundidad en los cuadrangulares o de herradura, ésta puede oscilar desde los o,8o hasta los 5,10 metros. Sin embargo, entre los de planta circular los hornos más comunes son aquellos con un diámetro comprendido entre los 2,00 y 4,00 metros (Figura 6A), ya que representan aproximadamente el 85\% del total frente a los demás hornos con la misma tipología de planta. En cambio, estos valores oscilan en el caso de los hornos de planta cuadrangular, de herradura o elíptica de entre 2,00 y 5,00 metros, siendo el $89 \%$ de los casos (Figura 6A).

En relación a la altura, la diferencia es incluso superior, ya que hay hornos que tienen menos de 1,00 metro de altura y en cambio otros que alcanzan los 6,00 metros. No obstante, la altura más común coincide con la dimensión en planta de los hornos circulares y oscila entre los 2,00 y 4,00 metros, aunque también destacan los hornos con una altura inferior a los 2,00 metros (Figura 6B). De igual modo, varía el espesor de los muros dependiendo de la envergadura del horno y de su materialidad (Figura 7) desde los 0,20 metros hasta alcanzar los casi 2 metros $(1,80 \mathrm{om})$ en algunos ejemplos (Figura $6 \mathrm{C}$ ), siendo el rango más frecuente comprendido entre 0,40 y o,80 metros (58\%) y el espesor más común de o,6o metros en el 24\% de los hornos dimensionados.

Asimismo, cabe señalar la capacidad volumétrica de los hornos dimensionados, un valor obtenido en 158 hornos, ya que es un factor directamente relacionado con la cantidad de piedra de yeso contenida en su interior, y por lo tanto calcinada y producida en cada hornada (Figura 6D). En este sentido, hay hornos en los que se podría calcinar aproximadamente más de $60 \mathrm{~m}^{3}$ de piedra de una vez, aunque la capacidad volumétrica más frecuente está comprendida entre 1 y $40 \mathrm{~m}^{3}$.

Por último, en general, mayoritariamente las principales dimensiones de los hornos están vinculadas con los sistemas de medidas tradicionales previos al sistema métrico, observándose una tendencia al uso de múltiplos del pie (y de la vara) para el dimensionado, también se establece una clara relación entre las dimensiones de los hornos medianos y las medidas antropométricas, relación básica para permitir que los operarios o yeseros pudieran cargar y descargar los hornos de forma manual sin la necesidad de emplear medios auxiliares que pudieran encarecer el proceso de producción. Además, salvo los casos excepcionales, en su conjunto las dimensiones

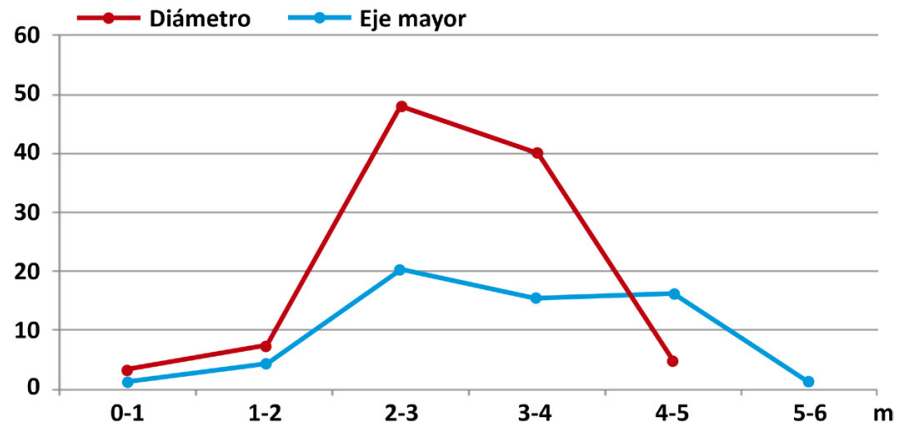

A. Según el diámetro y el eje mayor en la base.

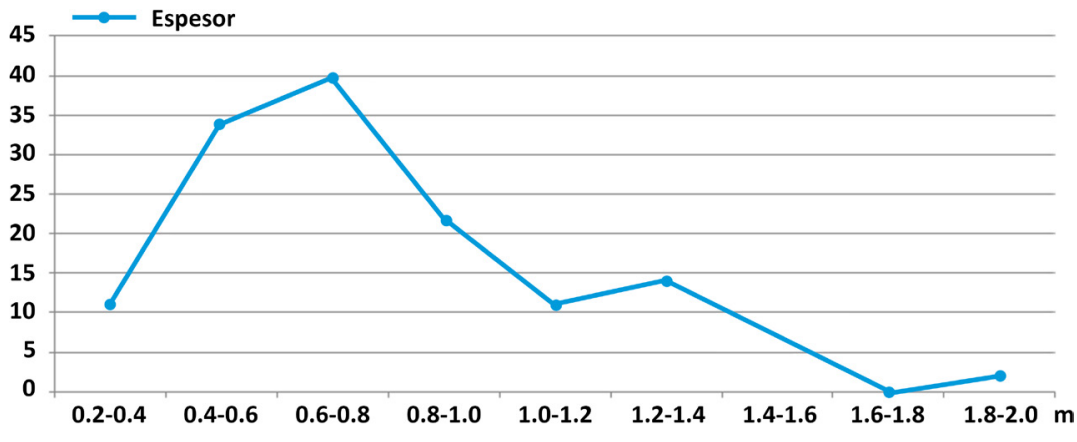

C. Según el espesor de los muros.

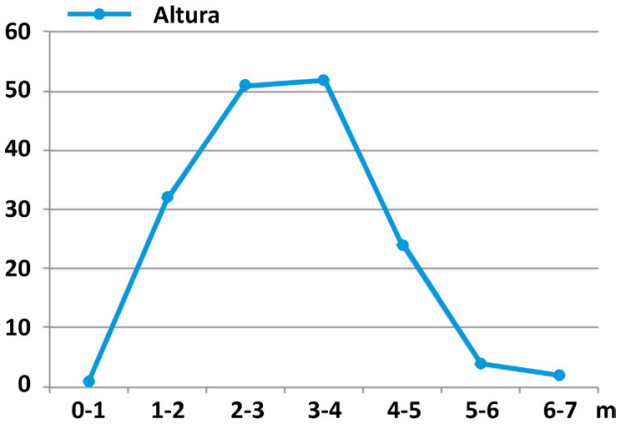

B. Según la altura.

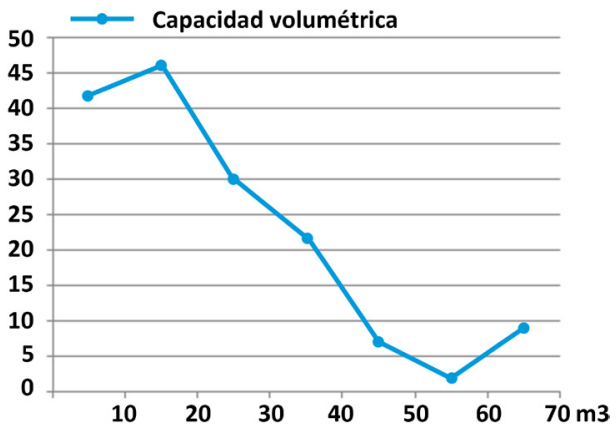

D. Según la capacidad volumétrica.

Figura 6. Rangos dimensionales de los hornos de yeso dimensionados. 


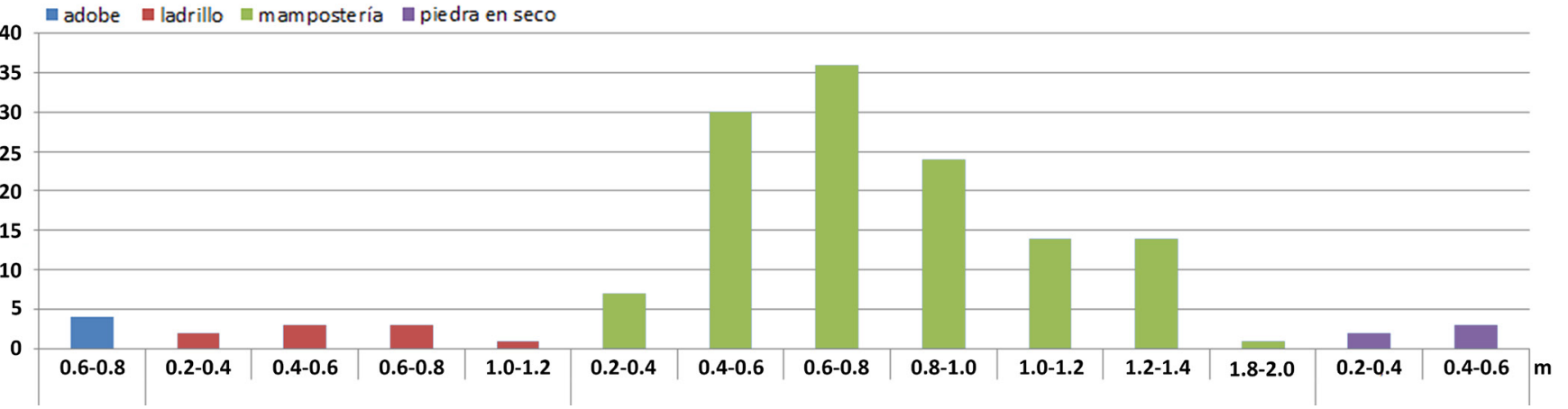

Figura 7. Relación entre la materialidad de la fábrica exterior y el espesor del muro de los hornos de yeso dimensionados.

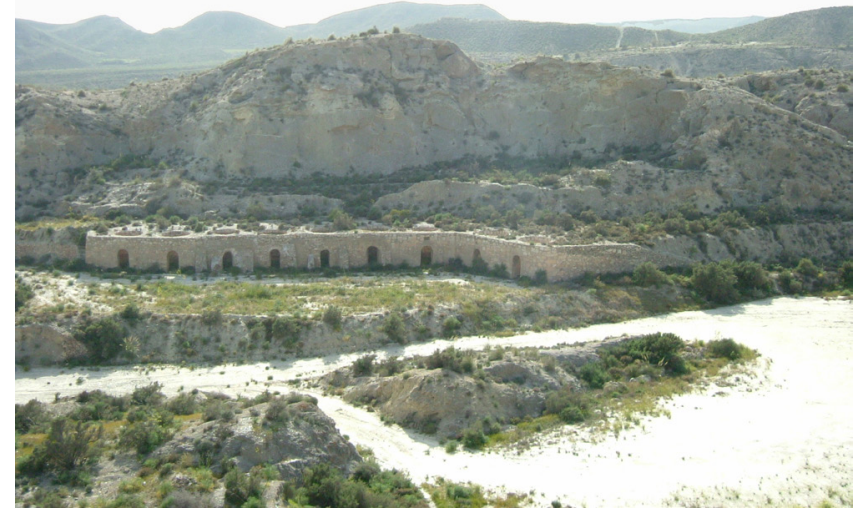

A. Conjunto de 9 hornos en Almería (Foto: Andrés Pérez Pérez).

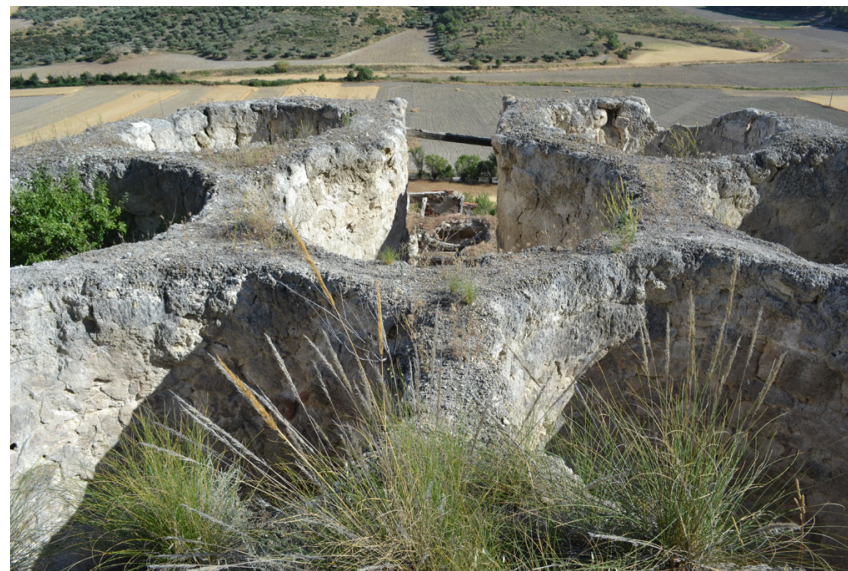

B. Grupo de 6 hornos en Valverde de Alcalá, Madrid (Foto: Autores, 2016).

Figura 8. Imágenes de diferentes hornos de yeso según aspectos morfológicos: disposición y número.

de los hornos están proporcionadas entre sí para lograr que la calcinación de la piedra de yeso fuera lo más uniforme y homogénea posible.

\subsubsection{Disposición y número de los hornos de yeso}

Los hornos tradicionales de calcinación de yeso pueden encontrarse, atendiendo a su emplazamiento en el lugar, exentos, semienterrados o enterrados en una ladera, siendo lo más común y frecuente que sean semienterrados en una ladera representando al $72 \%$ de los hornos inventariados. De este modo, se consigue aprovechar la inercia térmica del terreno, protegerlos del viento y facilitar también a la vez su carga o descarga por la parte superior (7).

Asimismo, según su disposición pueden hallarse aislados o en grupo, es decir, siendo simples construcciones individuales o formando parte de un conjunto compuesto por varios hornos que normalmente son tangentes o comparten un muro o pared, por lo que, se disponen bien alineados o bien agrupados. En España, las dos posibilidades son igualmente extendidas, ya que del total de centros de trasformación de yeso inventariados durante el estudio un $54 \%$ de ellos está compuesto por un único horno, mientras que el $46 \%$ por un conjunto de varios. Éstos últimos están formados principalmente por 2 hornos (70\%), en un menor número de casos por 3 hornos (25\%) y ya en casos excepcionales por 4, 5 o 6 hornos e incluso 9 y 14. En este sentido, cabe destacar por su singular disposición los hornos séxtuples en Valverde de Alcalá, Madrid (18), que se hallan colocados geométricamente alrededor de un hueco cilíndrico abierto componiendo exteriormente un pentágono
(Figura 8A) y el conjunto formado por 14 hornos también dispuestos tangencialmente en Valdemoro, Madrid (19), así como, el complejo situado en Almería y conocido como "El Cigarrón” compuesto por 9 hornos tangentes (Figura 8B).

$\mathrm{Al}$ igual que las dimensiones del horno y su capacidad volumétrica, el número de hornos existentes en un centro de transformación de yeso incide directamente en el tipo de producción obtenida. Por lo tanto, los hornos individuales son más frecuentes cuando la producción ha sido, por una parte, de tipo autosuficiente o puntual, es decir, para la construcción de un determinado edificio y por otra parte, más rudimentaria, sin formar parte de complejos en los que también se ha molido y cribado el aljez calcinado. En cambio, los hornos en grupo, por normal general, están asociados a fábricas o yeseras más modernas y por ello a centros de producción preindustrializados o industrializados de yeso artesanal por la cantidad producida, ya que de este modo la calcinación se realizaba de manera alterna entre los varios hornos o incluso simultánea, aunque muy raramente. Así pues, según los yeseros entrevistados, con el objetivo de no parar la producción en el caso de los hornos dobles, uno se calcinaba mientras el otro se descargaba o cargaba, en cambio, en los hornos triples, uno se calcinaba, el contiguo se descargaba y el siguiente se cargaba, obteniendo así una producción ininterrumpida de yeso calcinado.

\subsection{Aspectos funcionales: tipo de carga o armado de los hornos de yeso}

La carga o armado de un horno tradicional supone disponer las piedras de yeso de forma ordenada y siguiendo diversos 
criterios para crear un hogar o cuevas donde poder colocar e introducir en su interior el combustible para su calcinación y permitir situar el resto de piedras con diversos tamaños descendientes por la parte superior hasta rellenarlo por completo.

En este sentido, es posible diferenciar dos técnicas diferentes que consisten bien en la creación de una falsa cúpula asociada principalmente con los hornos de planta circular o bien en la realización de una o varias falsas bóvedas tanto en hornos de planta de herradura como cuadrada o rectangular. En el primer caso, los yeseros construyen con grandes piedras de yeso una falsa cúpula para que sea el hogar con una boquera abierta en el frente y así poder alimentar el horno. Tras cerrar la cúpula cargan el cilindro con más aljez construyendo simultáneamente el muro sobre la boquera de cierre del horno y por último vierten los restos y el polvo sobrantes para colmatar todos los intersticios (Figura 9A). Además, la cúpula según las dimensiones del horno puede ser de diferentes tamaños, permitiendo incluso crear un hogar donde se podría refugiar un hombre como en el caso de la localidad de Carrión de Calatrava, Ciudad Real (1). En cambio, en el segundo caso, bien se crean tres muros perpendiculares a la boca del horno, si el horno tiene una planta en forma de herradura para crear dos hogares, o bien muros paralelos a las paredes laterales del horno, si es de planta cuadrangular, rematados en todo caso por una falsa bóveda para formar los hogares que permiten alimentar el horno continuamente y administrar mejor el fuego, además de rellenarlo superiormente hasta la coronación, como en el primer caso. La ventaja de esta solución es que permite continuar con la calcinación del horno incluso en el caso en que una de las bóvedas se derrumbe, ya que si las dimensiones del horno lo permiten es incluso posible crear múltiples bocas (Figura 4C y 9B) y no exclusivamente dos. Además, en algunos ejemplos inventariados los hornos posen una "banqueta", saliente o repisa en su interior, a determinada altura, para facilitar la creación de la cúpula o la bóveda y ampliar el espacio del hogar, alejando a su vez las piedras del contacto directo con el fuego y el terreno.

\section{DISCUSIÓN}

El estudio y análisis realizado por una parte ha permitido conocer con más detalle la tipología de hornos que históricamente han sido utilizados en España para calcinar el aljez y así obtener yeso en polvo, un material con un papel destacado en la arquitectura tradicional española. Por otra parte, también ha consentido descubrir como los hornos empleados tradicionalmente no son simplemente parecidos a los de cal ni tampoco son todos de planta cuadrangular; y además simultáneamente evidenciar como sus rasgos constructivos, morfológicos y funcionales (Figura 10) están íntimamente relacionados entre ellos y también con el tipo y el carácter de la producción obtenida, así como con aspectos geográficos.

Desde una perspectiva constructiva, no se trata de obras monumentales, salvo algunos casos puntuales, ni tampoco de una excesiva complejidad técnica, aunque sí presentan un mayor nivel de sofisticación aquellas construcciones de carácter permanente o industrializado. Además, destaca el uso de técnicas constructivas tradicionales, sencillas y ampliamente empleadas en el pasado, así como el empleo de soluciones que representan un claro ejemplo de la economía de recursos que ha caracterizado, en general la arquitectura vernácula española y en particular la producción tradicional del yeso.

Atendiendo al aspecto morfológico de los hornos de yeso analizados, en primer lugar, puede establecerse una correspondencia entre el tipo de producción con el número y tamaño del horno, ya que por norma general, la existencia de hornos de menores dimensiones así como aislados o simples, puede vincularse más con una producción autosuficiente o esporádica, mientras que un mayor número de hornos o con dimensiones considerablemente superiores responde a una producción más especializada e incluso industrializada. En segundo lugar, según la información recopilada durante el estudio, todo apunta a que la principal diferencia tipológica formal existente entre los hornos de planta circular y cuadrangular puede estar más relacionada con cuestiones geográficas, territoriales o tradicionales, y en menor medida de tipo técnico o funcional. En este sentido, no es posible afirmar que las construcciones más industrializadas, y en consecuencia también más modernas, correspondan exclusivamente con hornos de planta cuadrada y de mayores dimensiones, ya que hay casos tanto de hornos cilíndricos con diámetros de hasta 4,50 metros como de hornos de construcción reciente para uso industrial también de planta circular. En general, los hornos con planta circular se caracterizan por tener una calcina-

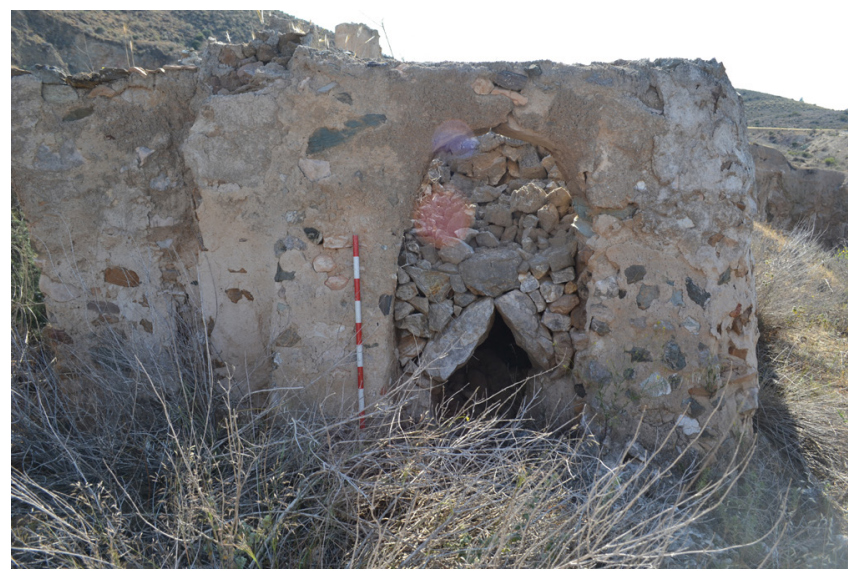

A. Horno circular cargado en la Rambla de las Yeseras de Mazarrón, Murcia.

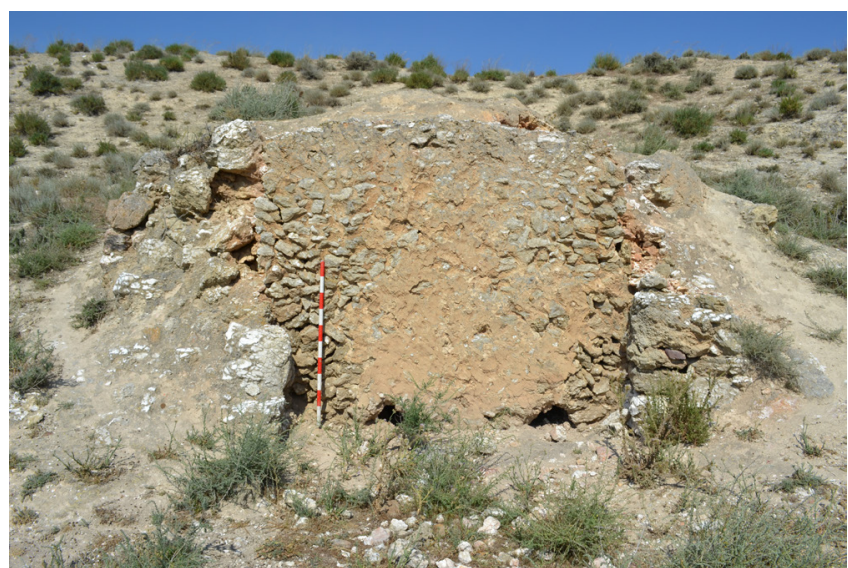

B. Horno rectangular cargado en Bardallur, Zaragoza.

Figura 9. Imágenes de diferentes hornos de yeso según aspectos funcionales (Fotos: Autores, 2016). 
ASPECTOS CONSTRUCTIVOS

Tipo de construcción

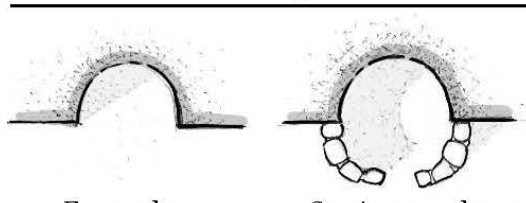

Excavada

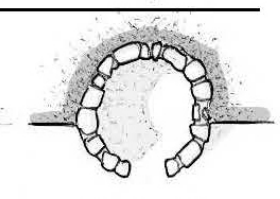

Construida

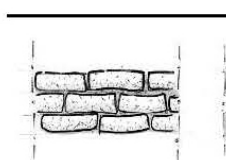

Adobe
Tipo de fábrica

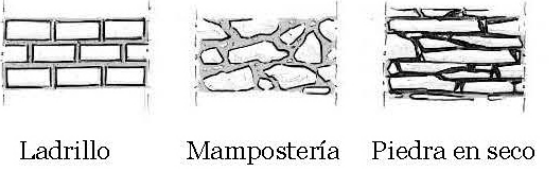

\section{ASPECTOS MORFOLÓGICOS}

Tipo de planta

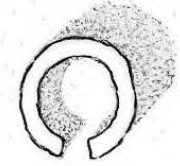

Circular

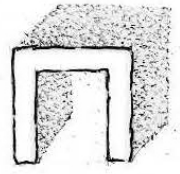

Cuadrangular Tipo de alzado

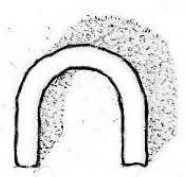

Herradura

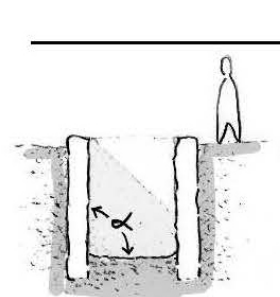

Cilíndrica Tipo de sección

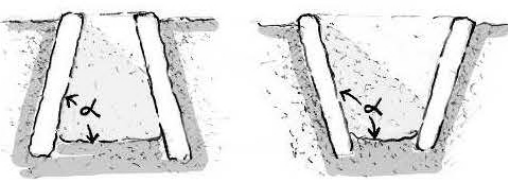

Troncocónica Troncocónica invertida Tipo de cubrición

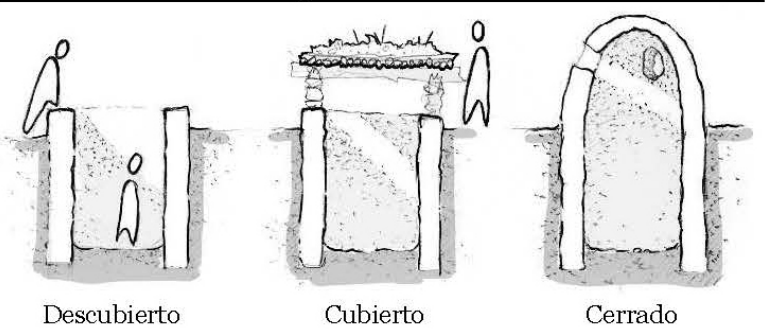

Tipo de tamaño

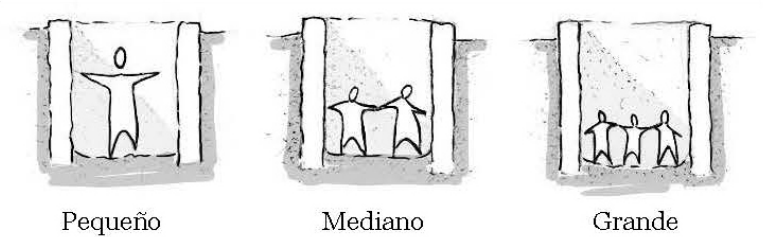

Tipo de situación

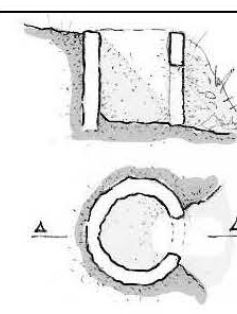

Enterrado

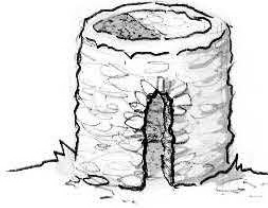

Cerrado
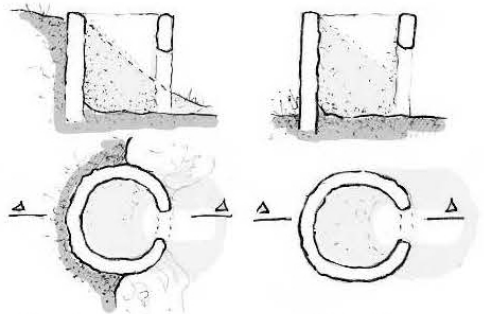

Semi-enterrado<smiles>CC1C=CC=CC=CC=C1</smiles>

Exento
Tipo de disposición

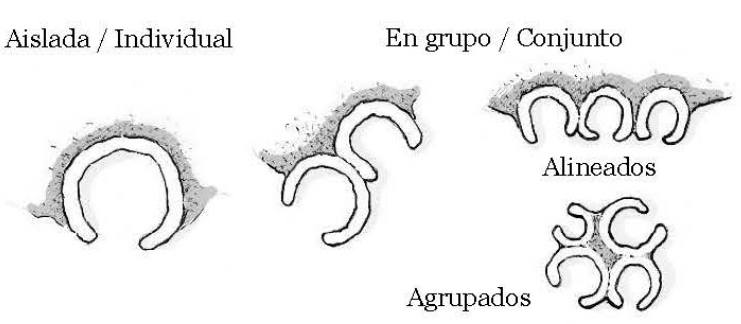

ASPECTOS FUNCIONALES

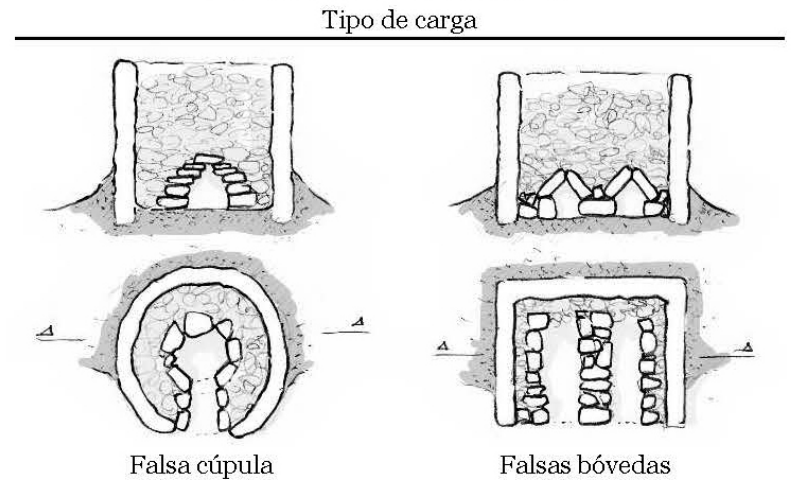

Figura 10. Esquema resumen de los tipos de hornos tradicionales de yeso en España (Dibujos: Autor 2, 2018). 
ción más uniformes que se obtiene con una menor cantidad de combustible, mientras que en los hornos de planta cuadrada o rectangular, ésta es más desigual, principalmente en las esquinas tal y como especifica Ger y Lobez en su tratado (9), y además requieren de mayores cantidades de combustible al crearse diferentes bóvedas que se calcinan simultáneamente. En consecuencia, quizás por ello los primeros se localizan geográficamente con frecuencia en zonas en las que la madera es un recurso escaso o en su lugar en áreas donde hay abundancia de monte bajo o matorrales como es el caso del sur de España. Al respecto, la tratadística histórica puntualiza que cuando hay escasez de leña los hornos se deben construir con una forma cónica truncada siendo el hogar su base mayor, y no de planta cuadrada (9) como ocurre en las localidades de Valldemosa (Islas Baleares) o Súria (Barcelona). De igual modo, la tipología de hornos completamente cerrados también responde a este mismo requisito. En cambio, en las áreas en las cuales no existe esta limitación, directamente relacionada con los recursos territoriales, las dos tipologías de hornos coexisten siendo incluso más abundantes los ejemplos de hornos de planta cuadrangular.

En relación con los rasgos funcionales, las proporciones dimensionales de los hornos y su situación en una ladera han favorecido en todo momento su carga y descarga, pero también una calcinación lo más uniforme posible en el interior del horno y evitar así diferencias de temperaturas excesivas. Además, existe una clara relación entre la forma en planta del horno y el tipo de armado, ya que la creación de una cúpula falsa caracteriza exclusivamente a los hornos de planta circular. Así como, la existencia de una indudable práctica local heredada y de una pericia empírica del yesero, en cada zona, con respecto a las diferentes técnicas de armado.

Asimismo, el estudio también ha permitido conocer como se ha producido un volumen considerable de yeso en polvo no exclusivamente en hornos de grandes dimensiones sino también en construcciones muy sencillas, rudimentarias y de tamaño medio, funcionando conjuntamente como verdaderos centros de producción, siendo el caso de la Rambla de Las Yeseras en Mazarrón (Murcia). En ella quedan aún restos de las 14 instalaciones compuestas por hornos dobles o triples donde, según un antiguo empleado, en el momento de máxima actividad se producía yeso como para cargar 9 camiones diarios $(20,1)$. Asimismo, otros ejemplos destacados son los conjuntos de hornos en Navarrete del Río, Calamocha (Teruel) o en Torrebaja, Ademuz (Valencia) (1).
Por último, cabe puntualizar que es muy complejo poder establecer una evolución cronológica clara en relación a las tipologías de hornos de yeso, y más teniendo en consideración que nuevos hornos de yeso se han construido en pleno siglo XX, en la provincia de València y de Murcia, reproduciendo la forma de los hornos tradicionales existentes en la zona (7), evidenciando claramente como el peso de la tradición se mantiene con el paso de los siglos independientemente de otros factores. De igual modo, puntualizar que la casuística tipológica de los hornos tradicionales de yeso en España aumenta de forma exponencial al poder combinarse varios de los criterios de clasificación analizados, ya que muchos de ellos no son excluyentes, sino acumulativos, multiplicándose así las posibles variaciones y diferencias.

\section{REFLEXIONES FINALES}

Los hornos tradicionales de yeso inventariados y analizados, junto con los centros de transformación que con frecuencia se levantaron para la producción de yeso en polvo constituyen un verdadero ejemplo del patrimonio arquitectónico e industrial español. Se trata en la mayoría de los casos de construcciones tradicionales que poseen un valor histórico, tecnológico, etnológico, arquitectónico y científico, que debe por tanto protegerse, recuperarse y revalorizarse. Además, la gran variedad tipológica que presentan los casos identificados, así como las particularidades o singularidades de algunos ejemplos, no solo son una clara muestra de que el mismo proceso de calcinación puede realizarse en construcciones diferentes, sino también de su complejidad constructiva, morfológica y funcional. Asimismo, su actual estado de conservación, relativamente bueno en la mayoría de los casos, aún consiente recordar procesos etnográficos íntimamente ligados con la construcción tradicional española y con el territorio donde se encuentran. Por lo tanto, se considera conveniente continuar con su identificación y descripción con el fin de ampliar y completar el inventario iniciado y de este modo no perder en el olvido parte de nuestra historia constructiva.

\section{NOTA}

Este artículo se enmarca en el "Estudio del yeso tradicional en España. Yacimientos, canteras, hornos y la arquitectura tradicional, su estado de conservación y propuestas de itinerarios visitables para su revalorización y difusión exp 2016C2000238”, realizado por los autores para el Instituto del Patrimonio Cultural de España en 2016.

\section{REFERENCIAS}

(1) La Spina, V. (2016). Estudio del yeso tradicional en España. Yacimientos, canteras, hornos y la arquitectura tradicional, su estado de conservación y propuestas de itinerarios visitables para su revalorización y difusión (Informe). Madrid: Instituto del Patrimonio Cultural de España, Ministerio de Educación, Cultura y Deporte.

(2) La Spina, V., Grau Giménez, C.J. (2020). Uses of gypsum in Spanish architectural heritage: Typologies and some unique construction techniques. International Journal of Architectural Heritage, 14(2): 176-195. https://doi.org/10.1080/155 83058.2018.1515275

(3) Riba Arteriu, O. y Macau Vilar, F. (1962). Situación, características y extensión de los terrenos yesíferos en España. En F. Hernández Pacheco (Eds.), I Coloquio Internacional sobre las obras públicas en los terrenos yesíferos (28p). Madrid: Servicio Geológico de Obras Públicas.

(4) Sanz Arauz, D. (2009). Análisis del yeso empleado en revestimientos exteriores mediante técnicas geológicas (Tesis doctoral). Universidad Politécnica de Madrid.

(5) Escavy, J.I., Herrero, M.J. y Arribas, M.E. (2012). Gypsum resources of Spain: Temporal and spatial distribution. Ore Geology Reviews, 49: 72-84. https://doi.org/10.1016/j.oregeorev.2012.09.001 
(6) Villanueva Domínguez, L. (2004). Evolución histórica de la construcción con yeso. Informes de la Construcción. Especial yesos, 56(493): 5-11. https://doi.org/10.3989/ic.2004.v56.i493.434

(7) Sanz Arauz, D. (2007). Hornos tradicionales de yeso para construcción. Recopar, 5: 76-84.

(8) La Spina, V. (2014). La calcinación industrial del yeso según la tratadística histórica. Anuario de Jóvenes Investigadores, 7: 111-113.

(9) Ger y Lobez, F. (1898). Manual de construcción civil. Badajoz: La Minerva Extremeña.

(10) Pereir y Gallego, P. (1853). Tesoro de Albañiles. Madrid: Antonio Martínez.

(11) La Spina, V., Grau Giménez, C.J. (2017). La evolución de la producción del yeso tradicional hasta los años 70 del siglo XX en Gestalgar, València (España). En S. Huerta, P. Fuentes y I. J. Gil Crespo (Eds.) Actas del Décimo Congreso Nacional y Segundo Congreso Internacional Hispanoamericano de Historia de la construcción (pp. 849-858). Madrid: Instituto Juan de Herrera y Escuela Técnica Superior de Arquitectura de Madrid.

(12) La Spina, V., Grau Giménez, C.J. (2017). El yeso en la Ribera del Xúquer: de la cantera a la obra. En I. Matoses Ortells, J. Hidalgo Mora y Planells Pérez, A. (Coords.) Arquitectura tradicional y patrimonio de la Ribera del Xúquer, Actas del segundo congreso comarcal de arquitectura y patrimonio, TRADIArq 2017 (pp. 260-277). Valencia: TC Cuadernos.

(13) Escudero Alcántara, A. (2009). 1520 Vegetación Gipsícola Mediterránea (Gypsophiletalia). En R. Hidalgo (Dir.) Bases ecológicas preliminares para la conservación de los tipos de hábitat de interés comunitario en España (78p). Madrid: Ministerio de Medio Ambiente, y Medio Rural y Marino.

(14) Bel-Anzué, P., Almagro, A., Sáez Pérez, M. y Rodríguez Navarro, C. (2017). Influence of the calcination process in traditional gypsum with structural behavior. Ge-Conservación, 1(11): 79-85.

(15) Vegas, F., Mileto, C., Fratini, F. y Rescic, S. (2010). May a building stand upon gypsum structural walls and pillars? The use of masonry made of gypsum in traditional architecture in Spain. En W. Jäger et al. (Eds.) Proceeding of the Eight International Masonry (10p). Dresden: Masonry Society and Technische Universität Dresden.

(16) La Spina, V. (2018). El yeso tradicional y sus oficios en España. En A. Galán Pérez y D. Pardo San Gil (Coords.) Las Profesiones del Patrimonio Cultural. Competencias, formación y transferencia del conocimiento: reflexiones y retos en el Año Europeo del Patrimonio Cultural 2018, (pp. 240-248). Madrid: GE-IIC y ACRE.

(17) García Guardiola, J. y Rizo Antón, C.E. (2011). Los yesares de Villena (Alicante). Arqueología y Etnología. Villena: Fundación Municipal "José María Soler”.

(18) Puche Riart, O., Mazadiego Martínez, L.F.; Llamas Borrajo, J. y Ortiz Menéndez, E. (2005). Yeserías y caleras de Valverde de Alcalá (Madrid). De Re Metallica, 5: 63-72.

(19) Puche Riart, O., Mazadiego Martínez, L.F.; Ortiz Menéndez, J.E. y Llamas Borrajo, J.F. (20o8). Yeserías históricas de Valdemoro, Madrid. En VI Congreso Internacional de Patrimonio Geológico y Minero, X Sesión Científica de la SE$D P G Y M$ (pp. 283-294). Madrid: SEDPGYM.

(20) Martínez Hernández, C. (2015). Las Yeseras, un paisaje geográfico cultural en abandono ligado al sistema constructivo tradicional. En IV Congreso Nacional de etnografía del Campo de Cartagena. La vivienda y la arquitectura tradicional del Campo de Cartagena (pp. 464-476). Cartagena: Universidad Politécnica de Cartagena. 